\title{
KINETIC MODELING STUDY FOR ACYLATION REACTION OF O-XYLENE TO 3,4-DIMETHYLBENZOPHENONE OVER H-BETA
}

\author{
Yusnimar \\ Jurusan Teknik Kimia Universitas Riau
}

\begin{abstract}
The reaction of o-xylene with benzoic anhydride has been studied by the changing molar ratio of the reactants $\left(20: 1,10: 1\right.$, and 5:1) in a batch reactor under reaction temperature $120^{\circ} \mathrm{C}$. The reaction carried out without catalyst and also with catalyst Zeolite beta which was activated at $300^{\circ} \mathrm{C}$ overnight. HPLC analysis results showed that the yield of the product increase with the changing molar ratio of the reactants. An attempt was made in determining the kinetics of the reaction. The results show that the reaction is neither first nor second order in the acylating agent. Obtaining the reaction order even initially is unsuitable for even simple reactions that do not go to completion. It is even less applicable where more than a single process which affects the rate is taking place right from the start. These might be any one or combination of diffusion, adsorption, desorption, inhibition of the reaction by the product and multi step reactions on the surface. Postulated reaction mechanisms may be required in combination with experimental data to determine even initial reaction orders.
\end{abstract}

Key words: o-xylene, catalyst, kinetics, reaction order.

\section{EFERENCES}

1. Smith, M.B., 2002, Organic Synthesis, $2^{\text {nd }}$ ed., Mc Graw Hill Co, Boston, p.65.

2. Bindhu, J., Sugunan, S., Singh, P.A., 1999, Selective benzoylation of o-xylene to 3,4-dimethylbenzophenone using various zeolites catalysts, J. Molecular Catalysis A-Chemical.,139: 43-45.

3. Creech, J., Ph. D., 1999, Thesis-UMIST.

4. Corma, A., Aguilar, J., Melo, F.V., Sastre, E., 2000, Alkylation of biphenyl with propylene using acid catalysts, Catalysis Today., 55: 1-2.

5. Chatterjee, A., Bhattacharya, D., Iwasaki, T., Ebina, T., 1999, A computer simulation study on acylation reaction of aromatic hydrocarbons over acidic zeolites, $J$. of Catalysis., 185: 23-27.

6. Andy, P., Garcia-Martinez, J., Lee, G., Gonzalez, H., Jones, C.W., and Davis, M.E., 2000, Acylation of 2methoxynaphthalene and isobutylbenzene over zeolite beta, J. of Catalysis., 192: 218-219.

7. Loenders, R., Jacobs, P.A., Martens, J.A., 1998, Alkylation of isobutane with 1butene on zeolite beta, J. of catalysis., 176 : 545- 547.

8. Deroune, E.G., Crehan, G., Dillon, C.J., Bethell, D., He, H., and Hamid, A., 2000, Zeolite catalysts as solid solvents in fine chemicals synthesis, $J$. of Catalysis., Vol 194: 410-413.

9. Haag, W.O.,1989, Mechanism of the protolytic cracking steps over acid zeolites, J. of Advance Catalysis., 1: 3-6.

10. Logan, S.R.,1996, Fundamentals of Chemical Kinetics, $1^{\text {st }}$ ed., Longman Group Ltd., London, 3-9.

11. Laidler, K.J., 1987, Chemical Kinetics, $3^{\text {rd }}$ ed., Harper 7 row Publisher, New York, 10-11, 21-23.

12. Yusnimar, 2002, Investigation of o- xylene conversion to 3,4- dimethylbenzophenone over zeolite beta, Graduate thesis of Department of Chemical Engineering- 
UMIST. United Kingdom: The University

of Manchester of Institute Science and Technology(UMIST) 